\title{
Self-referral and associated factors among patients attending adult outpatient departments in Debre tabor general hospital, North West Ethiopia
}

Tigist Misganaw Abere ${ }^{1 *}$, Desta Debalkie Atnafu ${ }^{2}$ and Yaread Mulu²

\begin{abstract}
Background: Self-referral leads to diminished quality of health care service; increase resource depletion and poorer patient outcomes. However, a significant number of patients referred themselves to the higher health care facilities without having referral sheets globally including Ethiopia. Even though the problem is much exacerbated in Ethiopia, there is limited evidence regarding self-referral patients in Ethiopia in particular in the study area.

Objective: To assess the magnitude and associated factors of self-referral among patients at the adult outpatient department in Debre Tabor general hospital, North West Ethiopia.

Method: Institution-based cross-sectional study was conducted from March 11-April 9, 2020 among 693 patients who attended adult outpatient departments. A systematic sampling technique was employed. Structured and pretested interviewer-administered questionnaire was used for data collection. Data were coded, cleaned and entered into Epi Info version 7.1 and exported to SPSS version 23 for further analysis. Binary logistic regression analysis was employed. In bivariable analysis $p$-value, less than 0.25 was used to select candidate variables for multivariable analysis. $P$-values less than 0.05 and $95 \%$ confidence intervals were used to select significant variables on the outcome of interest.

Result: The proportion of self-referral was $443(63.9 \%)$ with $95 \% \mathrm{Cl}(60.5 ; 67.5)$. Formally educated, (AOR = 1.83; (95\% Cl: 1.12, 3.01)), enrolled to Community Based Health Insurance (AOR $=1.57$; $(95 \%$ Cl: 1.03, 2.39)), poor knowledge about referral system ( $A O R=2.07 ; 95 \% \mathrm{Cl}:(1.28,3.39)$ ), not and partially available medication in the nearby Primary Health Care facilities ( $\mathrm{AOR}=2.12 ;(95 \% \mathrm{Cl}: 1.82,6.15)) \&(\mathrm{AOR}=3.24 ;(95 \% \mathrm{Cl}: 1.75,5.97))$ respectively and history of visiting general hospital ( $A O R=1.52 ;(95 \% \mathrm{Cl}: 1.03,2.25))$ were factors statistically associated with self-referral.

Conclusion and recommendation: The proportion of self-referral was low compared to the Ethiopian health sector transformation plan 2015/16-20. Socio-demographic and institutional factors were associated with self-referral. Therefore, regional health bureau better to work to fulfill the availability of medications in the primary health care facilities. In addition, Community Based Health Insurance (CBHI) agency should work to implement the law of out-ofpocket expenditure which states to pay 50\% for self-referred patients who claim utilization of healthcare.
\end{abstract}

\footnotetext{
* Correspondence: tigistabere3@gmail.com

${ }^{1}$ College of Medicine and Health Science, Bahir Dar University, Bahir Dar, Ethiopia

Full list of author information is available at the end of the article
}

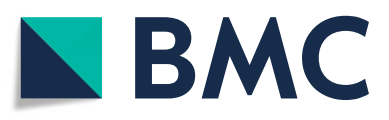

() The Author(s). 2021 Open Access This article is licensed under a Creative Commons Attribution 4.0 International License, which permits use, sharing, adaptation, distribution and reproduction in any medium or format, as long as you give appropriate credit to the original author(s) and the source, provide a link to the Creative Commons licence, and indicate if changes were made. The images or other third party material in this article are included in the article's Creative Commons licence, unless indicated otherwise in a credit line to the material. If material is not included in the article's Creative Commons licence and your intended use is not permitted by statutory regulation or exceeds the permitted use, you will need to obtain permission directly from the copyright holder. To view a copy of this licence, visit http://creativecommons.org/licenses/by/4.0/. The Creative Commons Public Domain Dedication waiver (http://creativecommons.org/publicdomain/zero/1.0/) applies to the data made available in this article, unless otherwise stated in a credit line to the data. 


\section{Plain English summary}

An effective referral linkage is an integral component of a successful health care system for quality health service. Many developing countries have policies regarding referral system while transforming referral policies into practice between primary health care (PHC) facilities and higher-level facilities is challenging. This study was trying to answer the magnitude and factor associated with self-referral through structured interview questionnaires.

The participants were asked about their socio-demographic characteristics, institutional related characteristics. There were 690 participants in this study. This study showed that the magnitude of self-referral was $63.9 \%$. Educational status, knowledge about referral system, availability of medication in the nearby PHC facilities, enrollment to CBHI and history of visiting general hospital were factors significantly associated with self-referral.

In conclusion, the proportion of self-referral was low compared to the Ethiopian health sector transformation plan 2015/16-20. Educational status, knowledge about referral system, availability of medication in the nearby PHC facilities, enrollment to $\mathrm{CBHI}$ and history of visiting general hospital were associated with self-referral. Policy action will be required to further improve ANC service utilization.

Keywords: Self-referral, Referral system and Ethiopia

\section{Introduction}

A referral system entails the interrelationship and coordination of patient care services from one health care facility to another. a referral is a process by which a health care worker transfers the responsibility of care temporarily or permanently to another health professional in response to their inability or limitation to provide the necessary care [1]. While self-referral is a situation when patients refer themselves to higher-level health care facilities other than the primary care facilities without having referral sheets [2].

An effective referral linkage is an integral component of a successful health care system for quality health service. Many developing countries have policies regarding to the referral system while transforming referral policies into practice between primary health care (PHC) facilities and higher-level facilities is challenging. To strengthen referral system all levels of the health care delivery system need to be functioning appropriately. In developing countries, higher-level health care facilities were overcrowded with patients who could be treated in lower level facilities which is a common feature of a poorly functioning referral system [3-6].

Self-referral causes depletion of resources such as patients waiting long hours and wasting of highly trained medical workers' time for minor cases. As a result, patients frequently referred to another hospital and die on the way. Moreover, due to the large patient load, human and physical resources are stretched to capacity, which results in hospitals compromising the care that they provide to patients [7].

The Ethiopian government has made remarkable progress to improve access to PHC units for all. According to the 2015 World health organization report, 1.6 billion dollars was financed for health care, of the total health expenditures, $14.69 \%$ goes to finance PHC. However, many patients attend a higher level of care for their initial visit that can be managed at a lower level without having a referral sheet [8-10]. As result, secondary level hospitals were congested and overburdened [2].

Studies conducted in Africa showed that the magnitude of self-referral was 27.7, $30.833 .9,60,87$ and 96.1\% in Nairobi Kenya, Mozambique, Ghana, Nigeria, Sudan and Kirinyaga district Kenya respectively [11-16]. In addition, the studies done in South Africa showed that the magnitude of self-referral was 35, 36, 86.9 and $88.2 \%$ in Kwazulu Natal, EThekwini District, Tubatse local Municipality and Western Cape province of respectively [17-20]. Similarly, studies done in Ethiopia the magnitude of self-referral in general and referral hospitals were 82 and $84.4 \%$ respectively [2, 21]. Additionally study conducted in Hosanna town, Hadiya Zone shows that $67 \%$ mothers bypassed their catchment public health centers [22].

Studies conducted in Sub Saharan Africa showed that respondents whose age is 40 years and below, sex of the respondents, income, educational level, distance, waiting time, availability of diagnostic test and medication, knowledge about the referral system and access to transportation were the factors that influence patient selfreferral $[11,14,15]$.

Similarly, studies conducted in Ethiopia showed that access to transportation, availability of laboratory service, availability of prescribed drugs and obtaining information about the referral system from health care worker at the nearby PHC facilities affected patient self-referral However, the relationship between self-referral and community based health insurance (CBHI) were not assessed $[2,6,21,23]$.

There are limited findings with regards to self-referral in our country and the study area. Therefore, the aim of this study was to assess the magnitude and factors 
associated with self-referral among patients at adult outpatient departments in Debre Tabor General Hospital.

\section{Methods \\ Study area}

The study was conducted in Debre Tabor comprehensive specialized hospital previously called Debre Tabor general hospital before September 2020. It is located in south Gondar zone which is $670 \mathrm{Km}$ far from Addis Ababa the capital city of Ethiopia. According to the Federal democratic republic of Ethiopia central statistics agency population projection of 2014-2017 reports, the total population of the South Gondar Zone was 2,484, 929 of whom 1,257,323 are men and 1,227,606 women [24]. There are 405-health posts, 96-health centers, eight primary hospitals and one comprehensive specialized hospital. The total population served by this hospital is 2.3 million peoples. The hospital catchment area includes four town administrations and 14 districts [25]. An institution-based cross-sectional study design was employed from March 11-April 9, 2020. All patients who attended the adult outpatient department in Debre Tabor General Hospital were our source population and selected patients who attended the adult outpatient department in Debre Tabor General Hospital were our study populations. Patients whose age 15 and above who visited adult outpatient departments during the study period were included while those patients who are critically ill/ unable to respond were excluded.

\section{Sample size and sampling procedure}

The sample size was determined by using both single population proportion formula and factor analysis while we found better sample size on objective one; based on the following assumptions, with Proportion of selfreferral patients $=82 \%$ [2], margin of error (3\%), 95\% CI. After adding $10 \%$ nonresponse rate, the final sample size was 693.

To recruit each participant's systematic sampling technique was employed by considering an average monthly patient flow of the hospital 6302 patients per month. The first participant was identified by lottery methods. Finally, every patient with 9th interval was included in the study until the final sample sizes were obtained.

\section{Study variables}

\section{Dependent variable}

Self-referral (Yes/No).

Independent variables Socio-demographic factors (Sex of the respondent, age of the respondent, wealth index, educational status, occupation, marital status and residence), Individual factors (Knowledge about the referral system, perceived severity of illness and perceived treatment at the general hospital is better) and Institutional factors (Distance, waiting time at PHC facilities, availability of diagnostic and medication at the nearby PHC facilities, access to transportation and obtaining information about referral system from health care workers).

\section{Operational definitions}

Self-referral self-referral is a situation when patients refer themselves to higher-level health care facilities (General Hospital) first before they visit primary health care facilities.

Knowledge about the referral system eight questions were used to measure the knowledge of patients with regard to the referral system. If the patients answer more than $75 \%$ of the knowledge question he/she was considered as having good knowledge, if the patients answer 45 to $75 \%$ he/she was considered as having fair knowledge and if they answer less than $45 \%$ they were considered as having poor knowledge [26].

Wealth index The socioeconomic status of each household was constructed using principal component analysis (PCA) of household assets followed by stratification of the households into wealth quintiles. The analysis was done by aggregating the ownership of durable assets; access to utilities and infrastructure; and housing characteristics; ownership of land and ownership of livestock variables into a single proxy variable of household wealth. All asset variables were coded into binary variables. Asset variables with zero standard deviations were excluded from the PCA as they did not contribute to the analysis. The first component of the PCA was used to construct the wealth quintiles. Based on the PCA weights for each asset variable, an aggregated score was calculated for each of the surveyed households, which was grouped into quintiles with quintile 1 (Q1) representing the poor $33 \%$ of households in the sample and quintile $3(\mathrm{Q} 3)$ representing 33\% of the better-off (rich). The study subjects were thereafter grouped into quintiles based on their household wealth [27-29].

\section{Data collection tools and procedures}

Structured and pretested interviewer-administered questionnaires were developed by reviewing different literatures $[12,14,15,21,30,31]$. First, the questionnaires were prepared in English then translated into the local language Amharic and translated back to English to check the consistency. The questionnaire consists of socio-demographic, individual and institutional factors. Data were collected via interview before obtaining service in the out-patient waiting area and training was 
provided for both data collectors and supervisors. Three-degree holder Nurses was recruited for data collection and one master holder were assigned for supervising data collection along with the principal investigator.

\section{Data quality control and assurance}

The Amharic version of the questionnaires was used to collect the data. A aretest was conducted among $70(10 \%)$ patients at Enjibara General Hospital before the study period to check the consistency of the questionnaire. Two days training was provided for data collectors and supervisors on the objective, the purpose, how to keep confidentiality, how to approach patients and how to take consent. The filled questionnaires were checked every day by the supervisor and every week by the principal investigator for completeness and consistency.

\section{Data analysis and management}

Data were coded, entered and cleaned in to Epi-Info version 7.1 and exported to SPSS version 23 for further analysis. Descriptive statistics (frequency, percentage, SD and mean) were employed to summarize the variables. Binary logistic regression analysis was employed to see the relationship between dependent and independent variables. Bivariable analysis was used to select the candidate variable for multivariable analysis at $p$ value less than 0.25 . Variance inflation factors (VIF) were used to check Multi-collinearity. $P$-values and confidence intervals were used to select significance variables on multivariable analysis and those variables whose $p$-value less than 0.05 were considered as statistically significant. Hosmer and Lemeshow test was used to check the model fitness.

\section{Results}

A total of 693 patients participated in this study with a response rate of $100 \%$.

\section{Socio-demographic characteristics of the respondents}

Two hundred ninety four (42.4\%) respondents were in the age groups of 35 and above years with the mean age and standard deviation of $34.3 \pm 11.9$ years. The majority of respondents $(52.4 \%)$ were living in urban. Two hundred sixty nine (38.8\%) respondents were not attended formal education while 98 (14.1\%) respondents attained degree and above. Two hundred thirty two (33.5\%) respondents were from the rich family wealth index. Two hundred sixty seven (38.5\%) respondents have good knowledge about referral system Three hundred sixty (51.9\%) respondents were not enrolled in CBHI (Table 1).
Table 1 Socio-demographic characteristics of the participants in Debre Tabor general hospital, $2020(n=693)$

\begin{tabular}{|c|c|}
\hline Variables & Frequency (\%) \\
\hline \multicolumn{2}{|l|}{ Age of the respondents } \\
\hline 15 to 24 & $156(22.5)$ \\
\hline 25 to 34 & $243(35.1)$ \\
\hline $35 \&$ above & $294(42.4)$ \\
\hline \multicolumn{2}{|l|}{ Sex of the respondents } \\
\hline Female & $350(50.5)$ \\
\hline Male & $343(49.5)$ \\
\hline \multicolumn{2}{|l|}{ Marital status } \\
\hline Single & $206(29.7)$ \\
\hline Married & $426(61.5)$ \\
\hline Widowed & $38(5.5)$ \\
\hline Divorced & $23(3.3)$ \\
\hline \multicolumn{2}{|l|}{ Educational status } \\
\hline No formal education & $269(38.8)$ \\
\hline Primary & $90(13.0)$ \\
\hline Secondary & $115(16.6)$ \\
\hline College diploma & $121(17.5)$ \\
\hline Degree \& above & $98(14.1)$ \\
\hline \multicolumn{2}{|l|}{ Occupation } \\
\hline Governmental employee & $99(14.3)$ \\
\hline Merchant & $124(17.9)$ \\
\hline Farmer & $223(32.2)$ \\
\hline Student & $120(17.3)$ \\
\hline Others & $127(18.3)$ \\
\hline \multicolumn{2}{|l|}{ Wealth Index } \\
\hline Poor & 232(33.5) \\
\hline Middle & $229(33.0)$ \\
\hline Rich & $232(33.5)$ \\
\hline \multicolumn{2}{|l|}{ Knowledge } \\
\hline Poor & 202(29.2) \\
\hline Fair & $224(32.3)$ \\
\hline Good & 267(38.5) \\
\hline \multicolumn{2}{|l|}{ Enrollment to CBHI } \\
\hline Yes & $333(48.1)$ \\
\hline No & $360(51.9)$ \\
\hline
\end{tabular}

Others = Daily laborers, NGO, Brokers, Drivers, Unemployed, house wife, and Tailor

\section{Institutional factors}

Five hundred two (72.4\%) respondents replayed that the health center is the closest health facility to their place of residence. Four hundred fifty two (70.8\%) respondents received information about the referral system from health care providers. Four hundred sixty seven (67.4\%) respondents have access to transportation. Four hundred 
thirteen (59.5\%) of the respondents have used a car as a means of transportation (Table 2).

\section{Magnitude of self-referral}

The magnitude of self-referral in this study was 443 (63.9\%) with $95 \%$ CI $(60.5 ; 67.5)$. The main reasons for self-referral were expected to get better treatment at the general hospital 63.1\%, not expected to get laboratory investigation 58.7 and $49.9 \%$ not expected to get medication at the nearby PHC facilities.

\section{Factors associated with patients self-referral}

In bivariable analysis educational status, place of residence, wealth index, history of visiting the general hospital, enrollment to CBHI, knowledge about referral system, distance to the health facilities, accessibility of

Table 2 Institutional related characteristics of the respondents in Debre Tabor general hospital, $2020(n=693)$

\begin{tabular}{ll}
\hline Variables & Frequency (\%) \\
\hline Nearby health facility closest to home & \\
Health center & $502(72.4)$ \\
Primary hospital & $155(22.4)$ \\
General hospital & $36(5.2)$
\end{tabular}

Visit nearby health facility for current health problem

$\begin{array}{ll}\text { Yes } & 551(79.5) \\ \text { No } & 142(20.5)\end{array}$

Availability of medication at PHC $(n=551)$

All available

78 (14.2)

Some available

$264(47.9)$

None available

$209(37.9)$

Availability of laboratory at PHC $(n=551)$

$\begin{array}{ll}\text { All available } & 65(11.8) \\ \text { Some available } & 178(32.3) \\ \text { None available } & 308(55.9) \\ \text { Waiting time at PHC }(\boldsymbol{n}=\mathbf{5 5 1}) & \\ \text { Too short } & 326(59.2) \\ \text { Too Long } & \text { 225(40.8) }\end{array}$

Distance from the hospital

Less than one hour 253(36.5)

One to two hour 67(9.7)

More than two hour 373(53.8)

Access to transportation

$\begin{array}{ll}\text { Yes } & 467(67.4)\end{array}$

No 226 (32.6)

Mode of transportation

Car $413(59.5)$

Animal 105 (15.2)

On foot $175(25.3)$ transport, availability of medication at the nearby $\mathrm{PHC}$ facilities, waiting times at $\mathrm{PHC}$ facilities were found be candidate variable for multivariable analysis at $p$-value less than 0.25 . On multivariable analysis educational status, history of visiting general hospital, Enrollment to $\mathrm{CBHI}$, knowledge about referral system and availability of medication at nearby PHC facilities were statistically significant at $p$-value less than 0.05 .

The odds of self-referral among patients who attend formal education was 1.83 times (AOR 1.83; (95\%; CI; $1.12,3.01)$ ) higher compared to those who did not have formally educated. The odds of self-referral among patients who were enrolled in CBHI was 1.57 times (AOR 1.57; (95\%; CI; 1.03, 2.39)) higher as compared to those who were not enrolled to CBHI. The odds of selfreferral among patients who have poor knowledge about the referral system was 2.07 times (AOR 2.07; 95\% CI $(1.28,3.39))$ higher compared to those patients who have good knowledge (Table 3 ).

The odds of self-referral among patients who replied that medication is not available at all and some medication is available at the nearby primary health care facilities were 2.12 (AOR 2.12; (95\% CI; 1.82, 6.15)) and 3.24 (AOR 3.24: (95\% CI; 1.75, 5.97) times greater compared to those who have got all the medication at nearby PHC facilities respectively. The odds of self-referral among patients who had a history of visiting General hospital was 1.52 times (AOR, 1.52; (95\%CI; 1.03, 2.25) higher compared to those who did not visit (Table 3 ).

\section{Discussion}

The magnitude of self-referral in the study area was $63.9 \%$ with $95 \%$ CI $(60.5 ; 67.5)$. This finding was consistent with a study conducted in Hadya Zone Ethiopia which shows that $67 \%$ [22] of the patients were selfreferral. However, the proportions of self-referral in this study was lower compared with studies conducted in western Ethiopia 84\% [21] and 82\% [2]. This difference might be attributed to the intervention that the Ethiopian HSTP focus to improve the accessibility and quality of PHC facilities since 2016 [8]. Moreover, the finding of this study was higher than a study conducted in South Africa which was 35\% [18] of patients in the outpatient department were self-referred. This may be due to in south Africa different family health service specialists assigned at $\mathrm{PHC}$ service to provide comprehensive specialty care to the community [32] while in Ethiopia specialty care is only delivered at higher health care facilities which are beyond the PHC level [8]. The Ethiopian government may take this lesson and should diversify healthcare services provided at the primary healthcare level in order to avoid unnecessary referrals.

The finding of this study showed that patients who attend formal education were more likely to be self- 
Table 3 Factor associated with self-referral among patients who attend Debre Tabor general hospital OPDs, 2020

\begin{tabular}{|c|c|c|c|c|}
\hline \multirow[t]{2}{*}{ Variable } & \multicolumn{2}{|c|}{ Self-referral } & \multirow[t]{2}{*}{ COR $(95 \% \mathrm{Cl})$} & \multirow[t]{2}{*}{ AOR $(95 \% \mathrm{Cl})$} \\
\hline & Yes & No & & \\
\hline \multicolumn{5}{|l|}{ Educational status } \\
\hline No formally educated & 131 & 138 & 1 & 1 \\
\hline Formally educated & 312 & 112 & $2.94(2.13,4.05)$ & $1.83(1.12,3.01)^{*}$ \\
\hline \multicolumn{5}{|l|}{ Residence } \\
\hline Urban & 273 & 90 & $2.86(2.07,3.94)$ & $1.19(0.62,2.31)$ \\
\hline Rural & 170 & 160 & 1 & 1 \\
\hline \multicolumn{5}{|l|}{ Enrollment to $\mathrm{CBHI}$} \\
\hline Yes & 275 & 85 & $3.18(2.29,4.39)$ & $1.57(1.03,2.39)^{*}$ \\
\hline No & 168 & 165 & 1 & 1 \\
\hline \multicolumn{5}{|c|}{ Knowledge about referral system } \\
\hline Poor & 152 & 50 & $2.41(1.62,3.59)$ & $2.07(1.28,3.39)^{*}$ \\
\hline Fair & 142 & 82 & $1.37(0.95,1.97)$ & $1.24(0.93,2.24)$ \\
\hline Good & 149 & 118 & 1 & 1 \\
\hline \multicolumn{5}{|l|}{ Wealth Index } \\
\hline Poor & 116 & 116 & 1 & 1 \\
\hline Middle & 153 & 76 & $2.01(1.38,2.93)$ & $0.81(0.39,1.66)$ \\
\hline Rich & 174 & 58 & $3.00(2.03,4.45)$ & $1.18(0.69,2.02)$ \\
\hline \multicolumn{5}{|l|}{ Distance } \\
\hline$<$ One hour & 215 & 158 & 1 & 1 \\
\hline 1 to $2 \mathrm{~h}$ & 44 & 23 & $1.41(0.82,2.42)$ & $1.09(0.67,1.76)$ \\
\hline 2 and more hour & 184 & 69 & $1.96(1.39,2.77)$ & $1.43(0.73,2.84)$ \\
\hline \multicolumn{5}{|c|}{ Availability of medication $(n=551)$} \\
\hline All available & 28 & 50 & 1 & 1 \\
\hline Some available & 174 & 90 & $3.45(2.04,5.85)$ & $3.24(1.75,5.97)^{*}$ \\
\hline None available & 123 & 86 & $2.55(1.49,4.38)$ & $2.12(1.82,6.15)^{*}$ \\
\hline \multicolumn{5}{|c|}{ Visiting General hospital previously } \\
\hline Yes & 251 & 110 & $1.66(1.22,2.27)$ & $1.52(1.03,2.25)^{*}$ \\
\hline No & 192 & 140 & 1 & 1 \\
\hline
\end{tabular}

referred to general hospitals compared to those who did not attend formal education. The finding of this study was consistent with study conducted in India [31]. This might be due to educated patients were perceived their illness to be unpredictable with worse outcomes [33] because of this they need more specialized care. In addition, education is one of the means to increase ones household income and they are more capable to spend money on the medical expenses [34]. And when people are educated they would know that better healthcare can be received in higher level health facilities.

This study identified patients who enrolled in CBHI were more likely to be self-referred compared to their counterparts. There is limited finding with the relationship between CBHI and self-referral. The reason for this might be patients who enrolled in CBHI cover low out- of-pocket payments for medical expenses hence they prefer high level and specialized health care service [35]. Thus, facilities should prohibit services for peoples with self-referrals who treated free of charges due CBHI claim right, Similarly CBHI agency should devise mechanisms of halting such unnecessary referrals.

The findings of this study showed that patients who have poor knowledge about the referral system were more likely to be self-referred compared to those patients who have good knowledge about the referral system. This finding was consistent with studies conducted in Nigeria [14] and Iran [36]. This might be due to knowledge is one of means to increases the understandings of the patients about the general service provision of the facilities and the chains of lower to higher health care facilities. Moreover, they are more likely to understand the existing referral system [37]. 
Patients who visit General hospital previously were more likely to be self-referred themselves compared to those who did not visit the service previously. This finding was consistent with a study conducted in Ghana [13]. The possible reason for this is they are more familiar with the provision of the services at the general hospital.

This study identified availability of medication at PHC facilities was associated with patient's self-referral. The finding of this study was in line with studies conducted in Ethiopia [2, 21] and South Africa [20]. This might be due to patients were more prefer to use facilities with available resources. Availability of health care resources in the facilities more attract the health care service users [38]. This implies that fulfilling the availability of medications at the lower health care facilities was reducing patient's self-referral.

\section{Limitation and strength}

This study might be prone to recall bias due to some of the variables assesses the respondents' previous experiences this may lead us the false results. To minimize these patients were asked the recent visiting experience of the facility.

\section{Conclusion}

This study shows that the proportion of self-referral in Debre Tabor general hospital was lower compare to the Ethiopian health sector transformation plan 2015/16-20 which stated that all individuals passed through primary health care services. Educational status, knowledge about referral system, availability of medication in the nearby PHC facilities, enrollment in CBHI and history of visiting general hospital were factors significantly associated with self-referral. Community-Based Health Insurance (CBHI) agency should work to implement the law of out-of-pocket expenditure which states to pay $50 \%$ for self-referred patients who claim utilization of healthcare.

\section{Abbreviations}

AOR: Adjusted Odds Ratio; CBHI: Community Based Health Insurance; Cl: Confidence Interval; COR: Crude Odds Ratio; FMOH: Federal Ministry of Health; HSTP: Health Sector Transformation Plan; OPD: Out Patient Department; PCA: Principal Component Analysis; PHC: Primary Health Care

\section{Acknowledgments}

First, our appreciation goes to Bahir Dar University, College of Medicine and Health Sciences. We would like to also thank Debre Tabor general hospital for giving me the necessary information for this study. Finally, we are also grateful to the supervisors and data collectors who have committed themselves throughout the study period and to all participants who were a volunteer to participate in the study.

\section{Authors' contributions}

TMA performs the development of the manuscript, develops the survey questioners, develops an interview guide; and collects the data, supervised the data collection, and analysis of the data. DD and YM support the methodology part of the study and analysis of the data. All authors read and approved the final manuscript.
Funding

No fund received for this research.

\section{Availability of data and materials}

The dataset/raw data used and/or analyzed during the current study available from the corresponding author on reasonable request.

\section{Declarations}

Ethics approval and consent to participate

Ethical clearance was obtained from Bahir Dar University College of Medicine and Health Science ethical review board. All methods were performed in accordance with the relevant guideline and regulations with the reference numbers 0095/2020. Permission letter was received from the college of medicine and health science research and development office and Debre Tabor General Hospital.

Informed consent was obtained from all patients and written informed consent was obtained from a parent and/or legal guardian if patients are under 18 years old. In addition, information was provided for the participant with regards to the purpose, the benefit, risk, the right of withdrawal at any stages of data collection and how could we maintain the confidentiality of the data.

\section{Consent for publication}

Not applicable.

\section{Competing interests}

The authors declare that there is no conflict of interest with regard to the publication.

\section{Author details}

${ }^{1}$ College of Medicine and Health Science, Bahir Dar University, Bahir Dar, Ethiopia. ${ }^{2}$ Department of Health System \& Health Economics, Bahir Dar University College of Medicine and Health Science, School of Public Health, Bahir Dar, Ethiopia.

Received: 26 January 2021 Accepted: 16 June 2021

Published online: 28 June 2021

\section{References}

1. Federal Democratic Republic of Ethiopia Ministory of Health. Guidline for implementation of a patient referral system. 2010.

2. Abdi WO, Salgedo WB, Nebeb GT. Magnitude and determinants of selfreferral of patients at a general hospital Western Ethiopia. Sci J Clin Med. 2015;4(5):86-92. https://doi.org/10.11648/j.sjcm.20150405.12.

3. Kamau KJ, Osuga BO, Njuguna S. Challenges facing implementation of referral system for quality health care services in Kiambu county, Kenya. Health Syst Policy Res. 2017:4(1):1-8.

4. Besancenot D, Sirven N, Vranceanu R. A model of hospital congestion in developing countries; 2018.

5. Pittalis C, Brugha R, Gajewski J. Surgical referral systems in low-and middleincome countries: A review of the evidence. PLoS One. 2019;14(9).

6. Gyedu A, Baah EG, Boakye G, Ohene-Yeboah M, Otupiri E, Stewart BT. Quality of referrals for elective surgery at a tertiary care hospital in a developing country: an opportunity for improving timely access to and cost-effectiveness of surgical care. Int J Surg. 2015;15:74-8. https://doi.org/1 0.1016/j.ijsu.2015.01.033.

7. Albutt K, Yorlets RR, Punchak M, Kayima P, Namanya DB, Anderson GA, et al. You pray to your god: a qualitative analysis of challenges in the provision of safe, timely, and affordable surgical care in Uganda. PLoS One. 2018;13(4): e0195986. https://doi.org/10.1371/journal.pone.0195986.

8. Health Sector Transformation Plan/HSTP/ 2015/16-20. 2015.

9. World Health Organization. Primary health care systems (primasys): case study from Lebanon: abridged version. World Health Organization; 2017.

10. Abrahim O, Linnander E, Mohammed H, Fetene N, Bradley E. A patientcentered understanding of the referral system in ethiopian primary health care units. PLoS One. 2015;10(10):e0139024. https://doi.org/10.1371/journal. pone.0139024

11. Wambui MF. Determinants of self-directed referral amongst patients seeking health services at Kenyatta National Hospital, Nairobi, Kenya. Kenya: Kenyatta University; 2013. 
12. Yao J, Agadjanian V. Bypassing health facilities in rural Mozambique: spatial, institutional, and individual determinants. BMC Health Serv Res. 2018;18(1): 1006. https://doi.org/10.1186/s12913-018-3834-y.

13. Yaffee A, Whiteside L, Oteng R, Carter P, Donkor P, Rominski S, et al. Bypassing proximal health care facilities for acute care: a survey of patients in a Ghanaian accident and emergency Centre. Tropical Med Int Health. 2012;17(6):775-81. https://doi.org/10.1111/j.1365-3156.2012.02984.x.

14. Okoli H, Obembe T, Osungbade K, Adeniji F, Adewole D. Self-referral patterns among federal civil servants in Oyo state, South-Western Nigeria. Pan Afr Med J. 2017;26. https://doi.org/10.11604/pamj.2017.26.105.11483.

15. Ahmed ME, Mahdi TE, Ahmed NJO. Bypassing primary health care facilities for common childhood illnesses in Sharg-Alneel locality in Khartoum state Sudan 2015. Science. 2017:5(2):77-87.

16. Kanyora JN. Factors contributing to patients bypassing the 2 nd and 3 rd levels of primary health care facilities in Kirinyaga districts. Kenya: Kenyatta University Institutional Repository; 2014

17. Becker J, Dell A, Jenkins L, Sayed R. Reasons why patients with primary health care problems access a secondary hospital emergency Centre. S Afr Med J. 2012:102(10):800-1. https://doi.org/10.7196/SAMJ.6059.

18. Rajman A, Mahomed O. Prevalence and determinants of self-directed referrals amongst patients at hospitals in eThekwini district, KwaZulu-Natal 2015. S Afr Fam Pract. 2019;61(2):53-9. https://doi.org/10.1080/20786190.201 9.1582213.

19. Magoro SM. Factors contributing to self-referrals of antenatal women for delivery at Dilokong Hospital, grater Tubatse local municipality; 2015.

20. Pillay I, Mahomed $\mathrm{OH}$. Prevalence and determinants of self referrals to a District-Regional Hospital in KwaZulu Natal, South Africa: a cross sectional study. Pan Afr Med J. 2019;33(4).

21. Geta ET, Belete YS, Yesuf EA. Determinants of Self-referral among Outpatients at Referral Hospitals in East Wollega, Western Ethiopia. BioRxiv. 2019:540476.

22. Elisso M. Assessement of the magnitude of bypassing public health center delivery service and associated factors among postnatal women in Nigist Eleni Memorial Hospital,Hossana town, Hadiya Zone,South Ethiopia; 2016.

23. Ghebreyesus TA, Fore $H$, Birtanov $Y$, Jakab Z. Primary health care for the 21 st century, universal health coverage, and the sustainable development goals. Lancet. 2018;392(10156):1371-2. https://doi.org/10.1 016/S0140-6736(18)32556-X

24. Centeral Statistical Agency of Ethiopia. Population projection of Ethiopia for all regions at wereda level from 2014-2017. Addis Ababa; 2013.

25. Debre Tabor General Hospital. Annual report 2019.

26. Abodunrin O, Akande T, Osagbemi G. Awareness and perception toward referral in health care: a study of adult residents in Ilorin, Nigeria. Ann Afr Med. 2010;9(3).

27. Vyas S, Kumaranayake L. Constructing socio-economic status indices: how to use principal components analysis. Health Policy Plan. 2006;21(6):459-68. https://doi.org/10.1093/heapol/czl029.

28. Ethiopian Central Statistics Agency (ECSA). Ethiopian demographic health survey (EDHS). 2016.

29. Rutstein SO. The DHS Wealth Index: Approaches for rural and urban areas; 2008

30. Tappis H, Koblinsky M, Doocy S, Warren N, Peters DH. Bypassing primary care facilities for childbirth: findings from a multilevel analysis of skilled birth attendance determinants in Afghanistan. J Midwifery Womens Health. 2016; 61(2):185-95. https://doi.org/10.1111/jmwh.12359.

31. Sabde Y, Chaturvedi S, Randive B, Sidney K, Salazar M, De Costa A, et al. Bypassing health facilities for childbirth in the context of the JSY cash transfer program to promote institutional birth: a cross-sectional study from Madhya Pradesh, India. PLoS One. 2018;13(1):e0189364. https://doi.org/10.13 71/journal.pone.0189364.

32. Bresick G, Von Pressentin KB, Mash R. Evaluating the performance of south African primary care: a cross-sectional descriptive survey. S Afr Fam Pract. 2019;61(3):109-16. https://doi.org/10.1080/20786190.2019.1596666.

33. Asnani MR, Barton-Gooden A, Grindley M, Knight-Madden J. Disease knowledge, illness perceptions, and quality of life in adolescents with sickle cell disease: Is there a link? Glob Pediatr Health. 2017;4:2333794X17739194.

34. Battistón D, García-Domench C, Gasparini L. Could an increase in education raise income inequality?: evidence for Latin America. Latin Am J Econ. 2014; 51(1):1-39. https://doi.org/10.7764/LAJE.51.1.1.

35. Collins D, Saya U, Kunda T. The impact of community-based health insurance on access to care and equity in Rwanda. Medford: Management Sciences for Health; 2016
36. Eskandari M, Abbaszadeh A, Borhani F. Barriers of referral system to health care provision in rural societies in Iran. J Caring Sci. 2013;2(3):229-36. https://doi.org/10.5681/jcs.2013.028.

37. Oluseye $\mathrm{O}$, Kehinde $\mathrm{D}$, Akingbade $\mathrm{O}$, Ogunlade $\mathrm{O}$, Onyebigwa $\mathrm{O}$, Oluwatosin O. Knowledge and utilization of referral system among health care workers in selected primary health care centres in Oyo state, Nigeria. J Community Med Prim Health Care. 2019;31(1):67-75.

38. Lamarche PA, Pineault R, Gauthier J, Hamel M, Haggerty J. Availability of healthcare resources, positive ratings of the care experience and extent of service use: an unexpected relationship. Healthc Policy. 2011;6(3):46-56. https://doi.org/10.12927/hcpol.2011.22178.

\section{Publisher's Note}

Springer Nature remains neutral with regard to jurisdictional claims in published maps and institutional affiliations.
Ready to submit your research? Choose BMC and benefit from:

- fast, convenient online submission

- thorough peer review by experienced researchers in your field

- rapid publication on acceptance

- support for research data, including large and complex data types

- gold Open Access which fosters wider collaboration and increased citations

- maximum visibility for your research: over $100 \mathrm{M}$ website views per year

At $\mathrm{BMC}$, research is always in progress.

Learn more biomedcentral.com/submissions 